[Regular Paper]

\title{
Research on Recognition Algorithm of Offshore Oil Pipeline Defect Inspection Based on Magnetic Flux Leakage Method
}

\author{
Tao JiN*, Peiwen Que, Liang ChEN, Tianlu CheN, and Liang Li \\ Dept. of Information Measurement Technology \& Instruments, Shanghai Jiao Tong University, \\ 1954 Huashan Road, Shanghai 200030, P. R. CHINA
}

(Received December 24, 2004)

\begin{abstract}
Pipeline safety evaluation is an important issue in the industry. Based on magnetic flux leakage (MFL) method, this paper presents an automated inspection device to inspect pipeline defects, analyzes the MFL inspection theory and some defect feature parameters, and gives a recognizing algorithm based on the dynamic wavelet basis function (WBF) neural network. The dynamic network utilizes multiscale and multiresolution orthogonal wavelet, through signals backwards propagation (BP), has more significant advantages than BP or other neural networks used in MFL inspection. It can also control the accuracy of the predicted defect profiles, possessing high-speed convergence and good approaching features. The performance applying the algorithm based on the network to predict defect profile from experimental MFL signals is also presented.
\end{abstract}

Keywords

Magnetic flux leakage, Pipeline inspection, WBF neural network, Multiresolution

\section{Introduction}

Corrosion, stresses and mechanical damages of oil and gas pipelines can result in catastrophic failures, so pipelines must be often inspected. In order to ensure the integrity of the system, the pipelines are periodically inspected for damage caused by corrosion and other factors using an inspection device called a 'pig'. Several different types of nondestructive evaluation (NDE) methods such as ultrasonic, X-rays method have been tried and tested for inspecting pipelines. Ultrasonic inspection robot is not sensitive to pipeline's material, and easier to measure thickness and classify defects. Its shortage is that it is designed only for performing pipeline crack inspections within a liquid medium because ultrasonic signal diminishes very soon in the air. X-Rays inspection robot also has a significant drawback to inspect inner pipeline. MFL method can be used to measure and locate cracks in both circumferential and axial directions, and it is the most popular method of pipeline inspection now, although it is sensitive to pipeline's material and easily interfered by other factors such as pipe material, inspection speed, and fluid pressure. Supported by China National High-Tech Research and Development Program (863 Program), we developed an pipeline inspection system based on

\footnotetext{
* To whom correspondence should be addressed.

* E-mail: jintly@sjtu.edu.cn
}

magnetic flux leakage methods to inspect offshore oil pipe defects, and this paper will mainly discuss how to recognize pipeline defect parameters utilizing wavelet basis function (WBF) neural network.

Artificial neural networks constitute a powerful class of nonlinear function approach for model-free estimation. They have been applied to pipeline inspection field for some years. Udpa worked on pipeline inspection inverse problems using neural networks ${ }^{1}$. Kang Yihua and Yang Lijian utilized neural networks to research signal processing of MFL inspection ${ }^{2), 3)}$. Wavelet basis function neural network is a new type of neural network, which uses wavelet transform multiresolution and multiscale features to construct a neural network. In this paper, orthogonal scaling functions are used to construct wavelet neural networks according to multiresolution theory, and a recognizing algorithm based on dynamic WBF neural networks is presented to obtain pipeline inspection defect parameters.

\section{Mathematical Model of Pipeline MFL Inspection}

Magnetic flux leakage nondestructive testing is an electromagnetic technique that can only be used for testing conducting material, and is originated from Michael Faraday's discovery of electromagnetic induction in 1831. Maxwell's Equations are used to describe electromagnetic fields, and their differential forms are expressed as follows: 


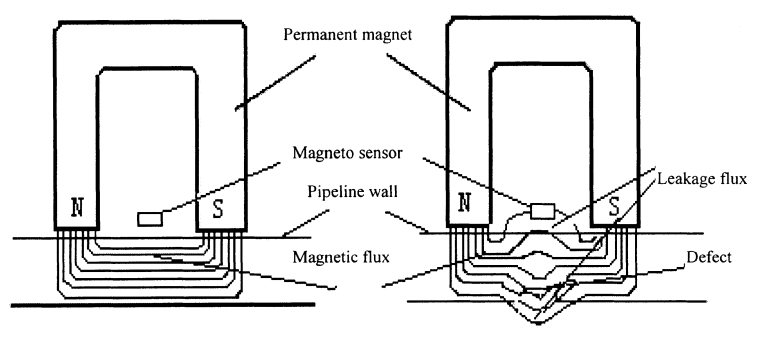

Fig. 1 Schematic Diagram of Magnetic Flux Leakage Inspection

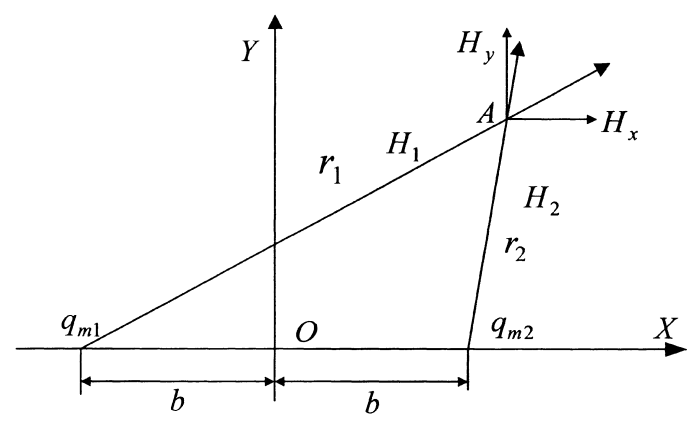

Fig. 2 Magnetic Dipole Theory Model

$$
\begin{aligned}
& \nabla \times \vec{E}=-\frac{\partial \vec{B}}{\partial t} \\
& \nabla \times \vec{H}=\vec{J}+\frac{\partial \vec{D}}{\partial t} \\
& \nabla \cdot \vec{D}=\rho \\
& \nabla \cdot \vec{B}=0
\end{aligned}
$$

Where $\vec{E}$ is electric field intensity, $\vec{H}$ is magnetic field intensity, $\vec{D}$ is electric flux density, $\vec{B}$ is magnetic flux density, $\vec{J}$ is electric current density, and $\rho$ is electric charge density. As shown in Fig. 1, utilizing permanent magnets to magnetize a sample to saturation, magnetic flux distributes equably in the sample when there is no defect. But in the regions of reduced thickness, such as a corrosion defect or crack, magnetic flux leakages into the air. This leakage flux, which is correlated with the size and location of the defect, can be detected by a magneto sensor. And then we can analyze pipeline defect parameters from the leakage flux signals.

The typical method to reconstruct defects distributing features is to utilize magnet dipole theory. Shown in Fig. 2, $H_{x}$ and $H_{y}$ are magnetic field intensions in $x$ and $y$ directions:

$$
\begin{aligned}
& H_{x}=\frac{q_{\mathrm{m}}}{4 \pi \mu_{0}}\left(\frac{x+b}{\left[(x+b)^{2}+y^{2}\right]^{3 / 2}}-\frac{x-b}{\left[(x+b)^{2}+y^{2}\right]^{3 / 2}}\right) \\
& H_{y}=\frac{q_{\mathrm{m}}}{4 \pi \mu_{0}}\left(\frac{y}{\left[(x+b)^{2}+y^{2}\right]^{3 / 2}}-\frac{y}{\left[(x+b)^{2}+y^{2}\right]^{3 / 2}}\right)
\end{aligned}
$$

Through calculating defects magnetic flux leakage intension, applying least-squares method, defect parameters and distributing figures can be obtained. However, the calculating workload is very tremendous, and the least-squares cost function is highly nonconvex with respect to the locations of magnetic dipoles, so it is now rarely adopted in pipeline inspection.

In fact, we can take a defect recognizing from inspection signals as a non-linear system discrimination problem. Based on 'MARMAX' model of non-linear system, when the system has $r$ inputs and $m$ outputs, the mathematical model of MFL inspection system can be described as:

$$
\begin{aligned}
y(k)= & f\left(y(k-1), \cdots, y\left(k-n_{y}\right), u(k-1), \cdots,\right. \\
& \left.u\left(k-n_{u}\right), e(k-1), \cdots e\left(k-n_{e}\right)\right)+e(k)
\end{aligned}
$$

Then we denote $y(k), u(k), e(k)$ as Eq. (4):

$$
y(k)=\left[\begin{array}{c}
y_{1}(k) \\
\vdots \\
y_{m}(k)
\end{array}\right], u(k)=\left[\begin{array}{c}
u_{1}(k) \\
\vdots \\
u_{r}(k)
\end{array}\right], e(k)=\left[\begin{array}{c}
e_{1}(k) \\
\vdots \\
e_{m}(k)
\end{array}\right]
$$

Where $y(k)$ and $u(k)$ are defect parameters outputs and pipeline inspection signal inputs respectively. $e(k)$ is the system independence noise which has limited mean-square deviation. $f(\bullet)$ is a non-linear vector function. $n_{\mathrm{y}}, n_{\mathrm{u}}, n_{\mathrm{e}}$ are the maximal time lapse of the outputs, inputs and noise respectively, and they are also named model steps. Equation (3) uses hysteresis inputs, outputs, and prediction errors to describe the function of MFL defects inspection, but in most occasions noise model step $n_{\mathrm{e}}$ has little impact on the system outputs, and it can be neglected, so Eq. (3) is simplified in practical operation process as:

$$
\begin{aligned}
y(k)= & f(y(k-1), \cdots, y(k-m), u(k-1), \cdots, \\
& u(k-n))+e(k)
\end{aligned}
$$

Utilizing Eq. (5), we present a new recognizing algorithm based on dynamic wavelet basis function neural networks to obtain the defect parameters including length, depth and etc. from inspection signals.

\section{Recognizing Algorithm Using Wavelet Basis Function Neural Network}

The wavelet transform is a time-frequency transform, which provides both the frequency and time localization in the form of a multiresolution decomposition of the signal. High frequency components are obtained with good time resolution and low frequencies with good frequency resolution ${ }^{4}$. A function can be reconstructed from its wavelet transform as

$$
W f(a, b)=\left(f, \psi_{a, b}\right)=|a|^{-1 / 2} \int_{R} f(x) \psi\left(\frac{x-b}{a}\right) \mathrm{d} t(6)
$$

Where $a$ is the dilation parameter, $b$ is the translation parameter, and $\psi(x)$ denotes mother wavelet. A wavelet 


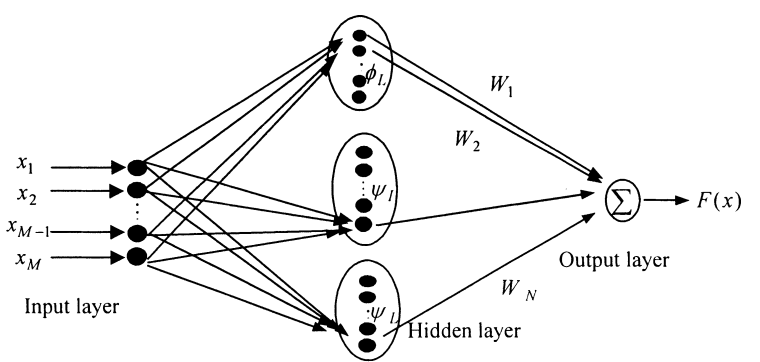

Fig. 3 The Structure of Wavelet Neural Network

based thresholding approach is utilized to eliminating noise. The technique is known as adaptive wavelet shrinkage denoising or soft thresholding. From the wavelet theory, we know that the dilations and translations of the orthogonal scaling function induce a multiresolution analysis of $L^{2}(R)$, i.e., a nested chain of closed subspaces:

$$
\cdots V_{1} \subset V_{-1} \subset V_{0} \subset V_{1} \subset V_{2} \cdots
$$

such that $\bigcap_{m} V_{m}=0, \quad \operatorname{clos} \bigcup_{m} V_{m}=L^{2}(R)$, where

$$
V_{m}=\operatorname{span}\left(2^{m / 2} \varphi\left(2^{m} x-n\right)\right)
$$

So there exists a sufficiently large $M$ for any $\varepsilon>0$, $f(x) \in L^{2}(R)$ can be approximated as

$$
\hat{f}(x)=\sum_{n}\left\langle f, \varphi_{M, n}\right\rangle \varphi_{M, n}(x)
$$

where $\|f(x)-\hat{f}(x)\|<\varepsilon$. Moreover, based on discrete wavelet multiresolution feature, when in the condition of resolution $2^{M}$ and orthogonal basis of $\psi_{m, n}(x)=2^{-m / 2} \psi\left(2^{-m} x-n\right)$, we can get the decomposing and reconstructing any non-linear functions as:

$$
\begin{aligned}
f(x) \approx f_{M}(x)= & \sum_{n=0}^{L} c_{0, n} \varphi_{0, n}(x)+ \\
& \sum_{m=0}^{M-12^{m-1}} \sum_{n=0}^{L} \widehat{c_{m, n}} \psi_{m, n}(x)
\end{aligned}
$$

The wavelet basis network is based on the theory of multiresolution representation of a function ${ }^{5}$. A WBF neural network architecture that implements a multiresolution approximation is shown in Fig. 3. The output of the network can be written as:

$$
F(x)=\sum_{j} W \Psi_{j}(x)
$$

As shown in Fig. 3, a static WBF neural network only shows the relation between its inputs and outputs generally. To improve the precision of the defects recognition, we can design a dynamic WBF neural network through signals backwards propagation. Its basic structure is shown as Fig. 4, and its output can be formulated as:

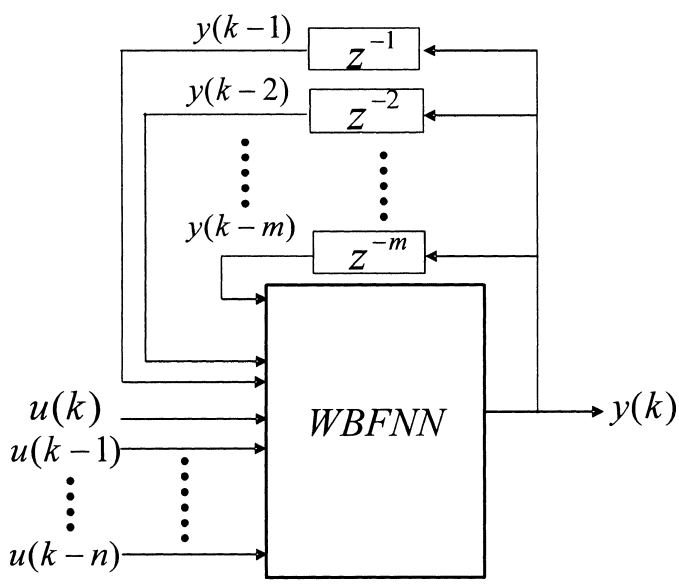

Fig. 4 Pipeline Defect Recognizing Dynamic WBF Neural Network

$$
\begin{aligned}
y(k)= & W N N[y(k-1), \cdots, y(k-m), \\
& u(k-1), \cdots, u(k-n)]
\end{aligned}
$$

Where $u(k)$ is the external input, $y$ is the output, $m$ and $n$ are the number of output and external input respectively. For the non-linear features of pipeline defects MFL inspection, we adopted three layers MIMO WBF neural networks to construct defects recognizing model. The first layer is input layer, and prompting function is orthogonal wavelet function; the second layer is hidden layer; and the third layer is output layer. A defined function $F(x)$ can describe the corresponding defect profile:

$$
\begin{aligned}
& F(x)=\sum_{j} W \Psi_{j}(x) \\
& =\sum_{j=1}^{N_{l}} s_{j}^{l} \phi_{j}^{l}\left(\left\|\bar{x}-\bar{c}_{j}\right\|\right)+\sum_{k=1}^{L} \sum_{j=1}^{N_{k}} d_{j}^{k} \psi_{j}^{k}\left(\left\|\bar{x}-\bar{c}_{j}\right\|\right)
\end{aligned}
$$

Where $\phi(x, c)$ is a scaling function, and $\psi(x, c)$ is a wavelet function, and $c_{j}$ is the centers of the basis functions. $L$ is the number of resolution.

$$
\begin{aligned}
& \phi(x, c)=\exp \left[\frac{\left\|\bar{x}-\bar{c}_{j}\right\|^{2}}{2 \sigma^{2}}\right] \\
& \psi(x, c)=\frac{\left\|\bar{x}-\bar{c}_{j}\right\|}{\sigma^{2}} \exp \left[\frac{\left\|\bar{x}-\bar{c}_{j}\right\|^{2}}{2 \sigma^{2}}\right]
\end{aligned}
$$

Then we can obtain the output error $e(f, F)$ and the squared error $E(f, F)$ :

$$
\begin{aligned}
& e(f, F)=\left\|f\left(x_{i}\right)-F\left(x_{i}\right)\right\| \\
& E(f, F)=\frac{1}{M} \sum_{i=1}^{M}\left(f\left(x_{i}\right)-F\left(x_{i}\right)\right)^{2}
\end{aligned}
$$

Through seeking the least squared error $E_{\min }(f, F)$, the output weights matrix can be obtained. So 


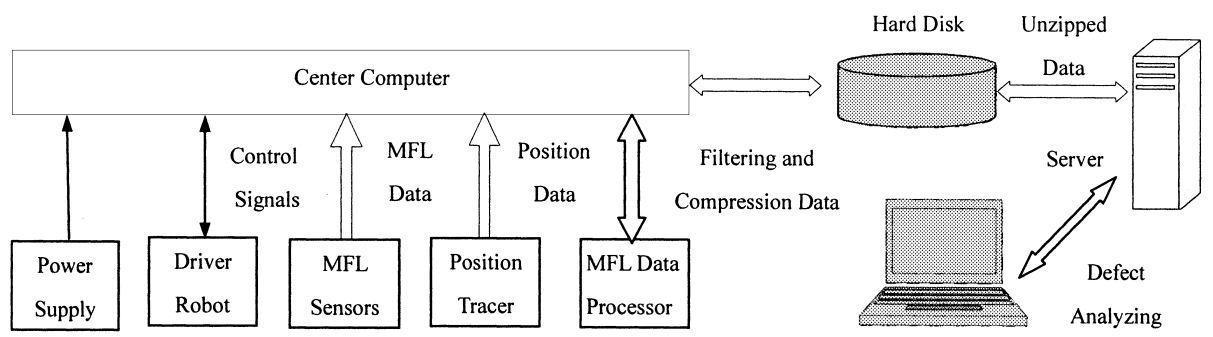

Fig. 5 Schematic Diagram of Pipeline MFL Inspection Device

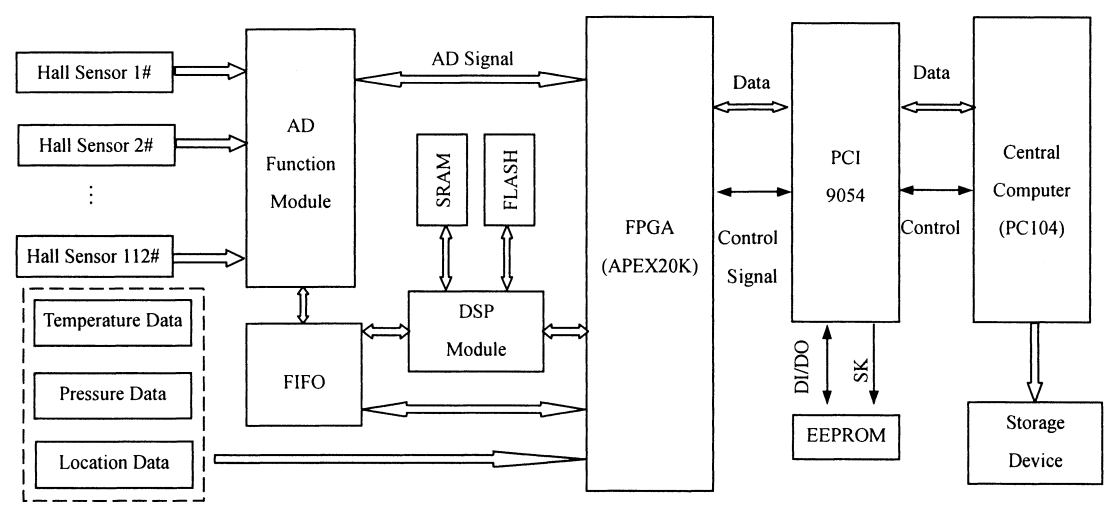

Fig. 6 Function Module Figure of MFL Inspection Robot Data Acquisition

$$
\begin{aligned}
& \frac{\partial E(f, F)}{\partial W_{i}}=0, \text { then } \\
& \frac{2}{M} \sum_{i=1}^{M}\left(f\left(x_{i}\right)-\left(\sum_{j} W \Psi_{j}(x)\right)^{l}\right)=0
\end{aligned}
$$

The selection of basis function centers is important to the network, and $k$-means clustering algorithm is usually adopted. We use a dyadic expansion scheme to select the location of centers which was presented by K. Hwang ${ }^{6}$. Concrete algorithm using the dynamic WBF neural networks presented as above for defect recognition is described as follows:

(1) Input MFL inspection data to the dynamic WBF neural networks;

(2) Set coarsest resolution as resolution $=0$;

(3) Select basic function centers $c_{j}$;

(4) Calculate input-hidden weights and hidden-output weights;

(5) Compare the squared error, if a calculated value is bigger than a given value, then go to the 2 nd step, increase the value of resolution, repeat the process.

(6) Output defects parameters and adjust basis function center $c_{j}$.

\section{Experiment Results and Discussion}

Figure $\mathbf{5}$ is the structure schematic diagram of offshore pipeline MFL inspection. The MFL inspection device has six parts: driver robot, system controller, power supply, MFL sensors, MFL data processor, and position tracer. The MFL pig adopts Hall sensors, having 112 pieces in axial and circumferential directions. The leakage flux signals are digitized and stored in the MFL data processor. Position tracer is used to trace defect location. From inspection signals we can estimate defect parameters such as length, and etc. Figure 6 is the data acquisition function module figure of the MFL inspection robot. The input signals include MFL signals, temperature data, pressure data, and location data. MFL inspection signals will be filtered in DSP module, and then compressed with other data in FPGA. Noise in pipeline inspection will affect recognition precision greatly, so we must eliminate noise signals from inspection signals, and an approach to eliminate noise aim at different noise sources based on adaptive filter and wavelet theory was presented ${ }^{7}$. Figure 7 is the filtering result of MFL inspection signal applying adaptive wavelet shrinkage denoising. Central computer (it is usual PC104) controls the data acquisition process through PCI9054. Finally, pipeline MFL inspection data are stored in storage device. Through many experiments and other 
researchers' work, we can get the main characteristic quantities of pipeline MFL defect signal as following:

(1) Signal waveform peak-peak value $p p$, which is a significant indication of a defect depth;

(2) Space between peak-peak $p-p$ can be used to measure a defect width;

(3) Area of signal waveform $S$ is the short time first order central moment of MFL inspection signal. It is formed by a waveform peak and a waveform valley, can be expressed as $S=\sum_{n}^{N}(x(t)-\min [x(t)])$;

(4) Waveform energy $E$, is equivalent to the short time second order central moment of MFL inspection signal, reflects MFL signal scattering degree, and $S=\sum_{n}^{N}(x(t)-\min [x(t)])^{2} ;$

(5) Other derivation characteristic quantity as,
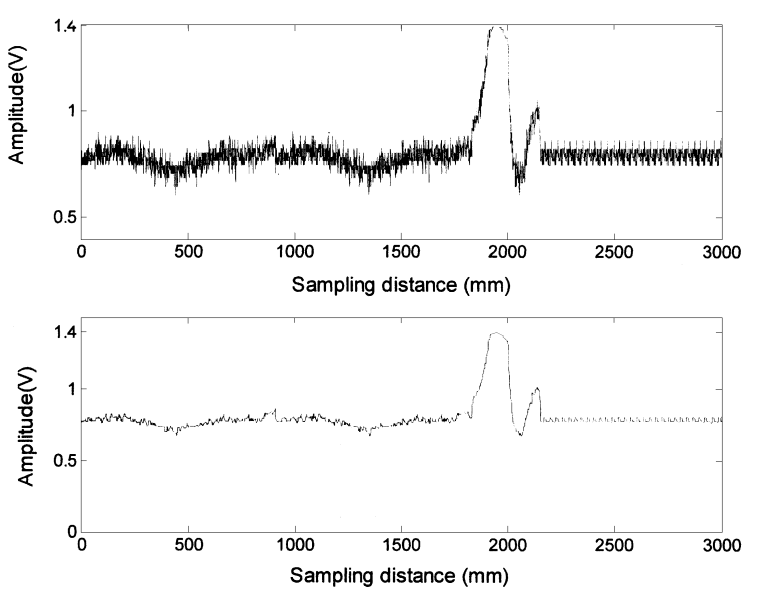

Fig. 7 MFL Inspection Signal Filtering Result Applying Adaptive Wavelet Shrinkage Denoising

Table 1 The Size Parameters of Chinese Offshore Oil Pipeline

\begin{tabular}{cccc}
\hline ID & Outer diameter & Thickness & Inner diameter \\
\hline $8 \#$ & $219 \mathrm{~mm}$ & $12,13 \mathrm{~mm}$ & $195,193 \mathrm{~mm}$ \\
$10 \#$ & $273 \mathrm{~mm}$ & $13 \mathrm{~mm}$ & $247 \mathrm{~mm}$ \\
$12 \#$ & $325 \mathrm{~mm}$ & $14.5 \mathrm{~mm}$ & $296 \mathrm{~mm}$ \\
\hline
\end{tabular}

$p p / p-p, S / p p, S / p-p$ and etc.

In the lab., we manufactured different defects as crack, corrosion utilizing electricity-sparkle methods on three types of pipelines which have the same material and sizes with Chinese offshore pipelines. Table 1 shows pipelines size parameters. When the MFL pig inspection speed is $14 \mathrm{~mm} / \mathrm{s}$ and the operation temperature is $23^{\circ} \mathrm{C}$, and no oil in the pipelines, we can get partial defect samples of MFL signals as Table 2.

Based on the methods presented in Section 3, combining pipelines signal characteristic quantities, we designed the input layer of the dynamic WBF neural networks recognizing algorithm having 4-6 nodes. As we all know, if the hidden layer has more nodes, it may have higher accuracy but the network training time is too long. On the contrary, when the network has several nodes, the defect recognition system has lower accuracy. Through many experiments, we found when the hidden layer is about 20 nodes, it could meet not only the needs of defect parameter output accuracy but also the real-time feature, so we set 20 nodes of hidden layer. Calculating for ease, the output layer has only depth, width, length nodes. Figures 8(a) and (b) are the recognizing results from a $10 \times 10 \times 1.3$ $\mathrm{mm}$ square defect by using the dynamic WBF neural network recognizing algorithm. The max network training steps is given as 3000 steps, and target error is 0.0001. Figure 8(a) shows the signal approaching curve and Fig. 8(b) shows the depth parameters approaching curve. Figure $\mathbf{9}$ is training precision and target precision curve diagrams with changing steps, and the network convergence step length is 1350 steps.

Through many experiments, the recognizing algorithm based on the dynamic WBF neural networks has good refining effects, and the accuracy can be controlled by varying the numbers of the network resolutions. The recognizing error rate is less than $0.5 \%$. The result is satisfied considering the MFL pig's inspection precision is $10 \mathrm{~mm}$. Table 3 is approaching precision comparison of BP and WBF neural network when they have same steps and same nodes of input layer, output layer, and hidden layer, and the convergence steps are usually no more than 4000, obviously

Table 2 Partial Defect Samples of MFL Signal

\begin{tabular}{cccccccccc}
\hline Defect ID & $\begin{array}{c}\text { Length } \\
{[\mathrm{mm}]}\end{array}$ & $\begin{array}{c}\text { Width } \\
{[\mathrm{mm}]}\end{array}$ & $\begin{array}{c}\text { Depth } \\
{[\mathrm{mm}]}\end{array}$ & $p p$ & $p-p$ & $S$ & $p p / p-p$ & $w$ & Shape \\
\hline 21 & 33.4 & 25 & 2.5 & 1.91 & 12.5 & 43 & 0.1528 & 27 & rectangle \\
22 & 20 & 20 & 1.6 & 1.29 & 11.7 & 33 & 0.1102 & 20 & rectangle \\
25 & 15.5 & 24.4 & 1.6 & 1.31 & 11 & 25 & 0.1191 & 25 & rectangle \\
35 & 10 & 10 & 0.8 & 0.65 & 8 & 11 & 0.08 & 12 & rectangle \\
38 & 10 & 10 & 1.3 & 0.98 & 8.1 & 18 & 0.121 & 11 & rectangle \\
49 & 10 & 10 & 2 & 1.63 & 8.2 & 27 & 0.199 & 11 & ellipse \\
53 & 400 & 20 & 3.5 & 2.63 & 13 & 75 & 0.2023 & 23 & ellipse \\
65 & 12 & 25 & 2 & 1.41 & 10.8 & 49 & 0.1306 & 29 & ellipse \\
71 & 9.5 & 11 & 1.3 & 1.03 & 9 & 32 & 0.1144 & 13 \\
\hline
\end{tabular}




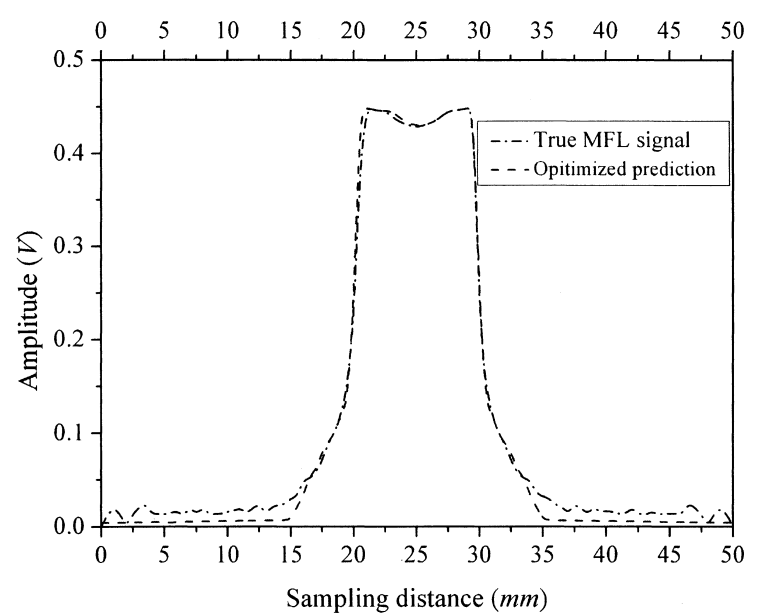

(a)

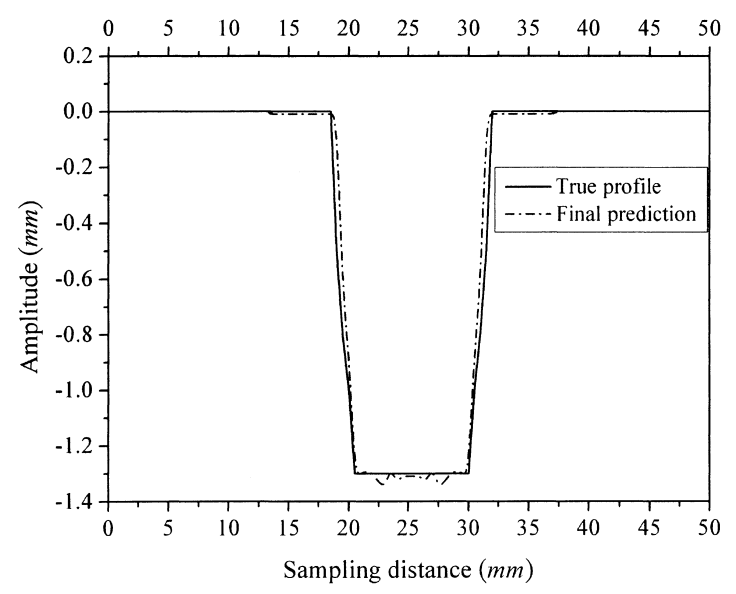

(b)

Fig. 8 Signal Approaching and Depth Approaching Curve of $10 \times 10 \times 1.3 \mathrm{~mm}$ Square Defect

having significant advantages than BP neural networks used in MFL inspection. Pipeline safety evaluation is a very important issue now, and there are more work which needs us to do. But only in the MFL pipeline defect recognizing field, how to improve the dynamic wavelet basis function neural network's output precision and select more efficiency centers and resolution, are our future research object.

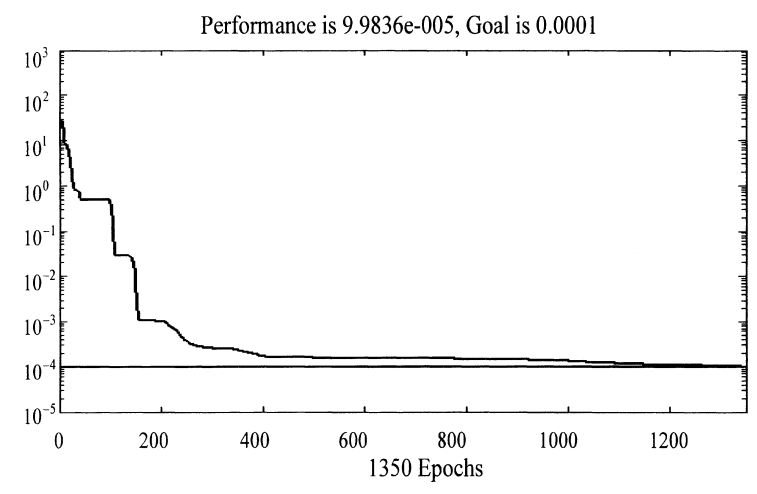

Fig. 9 Training Precision and Target Precision Curve Diagram with Changing Steps

Table 3 Approaching Precision Comparison of BP and WBF Neural Network

\begin{tabular}{ccccc}
\hline Network type & 1500 steps & 2000 steps & 2500 steps & 3000 steps \\
\hline BP & $74 \%$ & $81 \%$ & $86 \%$ & $90 \%$ \\
WBF & $82 \%$ & $86 \%$ & $94 \%$ & $97 \%$ \\
\hline
\end{tabular}

\section{Acknowledgments}

This work was supported by China National HighTech Research and Development Program (Number: 2001AA602021).

\section{References}

1) Ramuhalli, P., Udpa, L., Udpa, S. S., IEEE Transactions on Magnetics, 38, 3633 (2002).

2) Kang, Y., Wu, X., Yang, S., Nondestructive Testing, 22, 255 (2000).

3) Yang, L., Chen, X., Wei, J., Journal of Shenyang Polytechnic University, 21, 516 (1999).

4) Peng, Y., "Wavelet transform and engine applying," Science Publishing Co., China, (2000).

5) Rying, E. A., Bilbro, G. L., Jye-Chyi, L., IEEE Transactions on Neural Networks, 13, 304 (2002).

6) Hwang, K., Mandayam, S., Udpa, S. S., Udpa, L., Lord, W., IEEE 39th Midwest Symposium on Circuits and Systems, Vol. 3, Aug. 1996, p. 1420-1423.

7) Jin, T., Que, P., Journal of Test and Measurement Technology, 17, 359 (2003). 
要旨

\section{認識アルゴリズムを用いた海洋パイプラインの漏えい磁束探傷法}

Tao Jin, Peiwan Que, Liang Chen, Tianlu Chen, Liang Li

Dept. of Information Measurement Technology \& Instruments, Shanghai Jiao Tong University,

1954 Huashan Road, Shanghai 200030, P. R. CHINA

石油産業においては，海洋パイプライン等の安全評価は環境 污染あるいは人身事故を未然に防ぐという意味合いで非常に重 要なものである。その評価方法としては, 管厚の測定に対して 有効な超音波探傷法のほかに，パイプラインの管体に生じた微 小な傷を探知する手法として近年広く利用されるようになった 漏えい磁束探傷法がある。同手法は, 出力信号処理として ウェーブレット基底関数をスペクトル解析し, 時間情報と周波
数情報の両方を同時に解析して得られるものである。本論文で は, 漏えい磁束探傷法を用いたパイプラインの探傷自動化装置 の開発において検討されてきたウェーブレット基底関数ニュー ラルネットワークのダイナミックな反復アルゴリズム利用によ る検知精度の向上, ならびに高速化を図る手法について紹介し ている。 